\title{
Ivacaftor for the Treatment of Cystic Fibrosis Coexisting with Trisomy 21: A Case Report
}

\author{
Edward Charbek $^{1}$, Ghassan Kamel ${ }^{2}$, Ravi P. Nayak ${ }^{1}$ \\ 1. Internal Medicine, Saint Louis University School of Medicine, St. Louis, USA 2. Internal Medicine: Critical Care, Saint \\ Louis University School of Medicine, St. Louis, USA
}

Corresponding author: Edward Charbek, edward.charbek@health.slu.edu

\begin{abstract}
The association between cystic fibrosis (CF) and trisomy 21, or Down Syndrome (DS) is rare, and it pertains a poor prognosis with the majority of patients dying in infancy. We report a case of a 28 -year-old male with DS and moderate CF ( $\triangle \mathrm{F} 508 / \mathrm{G} 551 \mathrm{D}, \mathrm{FEV} 11.92 \mathrm{~L}, 60 \%$ predicted at the age of 18 years) diagnosed in childhood. The patient's lung function continued to deteriorate over time (FEV1 nadir of $1.29 \mathrm{~L}$ ), and he was started on ivacaftor in the year 2012 following ivacaftor release and approval. FEV1 and FVC improved significantly along with an increase in the patient's body mass index. Ivacaftor potentiates the openchannel probability of the G551D-CFTR. It has been shown to improve lung function, symptoms, weight, and sweat chloride concentration and decrease the risk of pulmonary exacerbations in patients with severe pulmonary CF (G551D). Our case argues against the reported literature of poor prognosis when the two chronic diseases coexist as only one case report in the literature described a DS patient with CF surviving into adulthood. In our patient, treatment with ivacaftor resulted in an increase in FEV1 and weight that exceeded the response observed in the ivacaftor landmark trial. Genetic studies are underway to understand the genetic basis of the large variation in DS phenotypes, which is probably caused by allelic heterogeneity on multiple chromosomes. The latter may explain the enhanced response observed in our patient and suggests that although patients with concomitant DS and CF may have worse lung disease, their response to novel therapies may be intensified. Further studies are needed in this subset of patient population to better characterize $\mathrm{CF}$ with trisomy and other genetic disorders.
\end{abstract}

Received 11/06/2019

Review began 11/10/2019 Review ended 11/14/2019 Published 11/18/2019

\section{() Copyright 2019}

Charbek et al. This is an open access article distributed under the terms of the Creative Commons Attribution License CC-BY 3.0., which permits unrestricted use, distribution, and reproduction in any medium, provided the original author and source are credited.
Categories: Pulmonology

Keywords: cystic fibrosis, ivacaftor, trisomy 21

\section{Introduction}

Cystic fibrosis (CF) is the most common genetic disorder in whites [1,2]. A mutation in the CF conductance transmembrane regulator (CFTR) gene, which codes for the CFTR protein, is responsible for the pathogenesis of the disease. There are more than 1,800 mutations identified in the pathogenesis of CF, which are classified into six classes. A class III mutation, G551D, is characterized by a dysfunctional CFTR protein on the cell surface that cannot transport chloride through its channel [3].

Down syndrome, caused by trisomy 21, is the most common chromosomal abnormality. It affects one in 600 to 800 live births. Respiratory conditions such as obstructive sleep apnea, asthma, pulmonary vascular disease, and parenchymal lung disease have been reported to be associated with Down syndrome $[4,5]$. The association between CF and Down syndrome is rare, and it pertains a poor prognosis with the majority of patients dying in infancy [6].

Ivacaftor, an oral CFTR potentiator, increases channel open probability (gating) of class III mutations. It has been shown to improve lung function, weight, and sweat chloride levels in clinical trials. Ivacaftor is an approved therapy for CF patients with several mutations such as G551D, G551S, G1349D, G970R, G178R, S549N, S1251N, and S1255P [7,8]. We report a case of a patient with Down syndrome and CF ( $\triangle F 508 / G 551 D)$, who has successfully transitioned to the adult CF program at our institution and is being treated with ivacaftor.

\section{Case Presentation}

A 28-year-old male with Down syndrome that was diagnosed shortly after birth based on clinical characteristics. Frequent respiratory infections during infancy prompted further investigation that led to the diagnosis of CF based on a sweat test results of $74 \mathrm{mmol} / \mathrm{L}$ and genotype analysis of $\triangle F 508 / \mathrm{G} 551 \mathrm{D}$. The patient had exocrine pancreatic insufficiency that affected his nutritional status during childhood as his weight was below 25 th percentile. He was able to improve his weight and achieve adequate growth after introducing pancreatic replacement therapy. At the age of 18 years, he transitioned to the adult CF program at our institution, and he had moderate CF with FEV1 of $1.92 \mathrm{~L}, 60 \%$ predicted. The patient had no significant changes on chest radiography. 
The patient had recurrent sinopulmonary infection and chronic Pseudomonas aeruginosa colonization; however, he did not have frequent CF-related pulmonary exacerbations requiring hospitalizations or home intravenous antibiotics.The patient's lung function continued to deteriorate over time, and FEV1 reached a nadir of $1.29 \mathrm{~L}, 42 \%$ predicted. Subjectively, he was feeling more dyspneic and became limited in his daily activities. In May 2012, he started ivacaftor and followed regularly with spirometry measurements to monitor disease progression. His lung volumes, particularly FEV1 and FVC, improved significantly along with increase in his body mass index.

Table 1 demonstrates treatment response overtime. Improvement in respiratory symptoms was reported by the patient as well. In fact, he was able to conduct his daily activities with minimal limitations, and he started working part time at a fastfood restaurant. He did not require any hospitalization during the time he was on ivacaftor.

\begin{tabular}{|c|c|c|c|c|c|}
\hline & FEV1 (L) & FEV1\% & FVC (L) & Weight (kg) & BMI $\left(\mathrm{kg} / \mathrm{m}^{2}\right)$ \\
\hline Baseline & 1.48 & 46 & 1.62 & 53.5 & 23.5 \\
\hline 12 months & 1.58 & 50 & 1.98 & 60.3 & 26.8 \\
\hline 60 months & 2.09 & 65 & 2.55 & 58.5 & 26.5 \\
\hline \multicolumn{6}{|c|}{$\begin{array}{l}\text { TABLE 1: Lung function and body mass index changes over time following treatment wit } \\
\text { ivacaftor }\end{array}$} \\
\hline \multicolumn{6}{|c|}{ FEV1: forced expiratory volume in one second, FVC: forced vital capacity, BMI: body mass index. } \\
\hline
\end{tabular}

\section{Discussion}

Ivacaftor potentiates the open-channel probability of the G551D-CFTR. It has been shown to improve lung function, symptoms, weight, and sweat chloride concentration and decrease the risk of pulmonary exacerbations in patients with severe pulmonary CF due to G551D mutation [8]. To our knowledge, this is the first case that demonstrates ivacaftor effectiveness in a patient with CF due to G551D mutation and Down syndrome.

The reported literature suggests poor prognosis when the two chronic diseases coexist as only one case report in the literature described a DS patient with CF surviving into adulthood [9-11]. In our patient, treatment with ivacaftor resulted in an increase in FEV1 and weight by 19 percentage points and $5 \mathrm{~kg}$, respectively, which significantly exceeded the response observed in the ivacaftor landmark trial of 10.6 percentage points and $2.7 \mathrm{~kg}$ in FEV1 and weight, respectively [8].

Down syndrome is the most common recognizable genetic syndrome associated with immune defects [12] with an increase in susceptibility to recurrent respiratory infection due to abnormal components of the immune system $[13,14]$. Airway abnormalities such as laryngomalacia and tongue and tonsillar enlargement, the increased prevalence of gastroesophageal reflux disease, and congenital ear abnormalities are among the non-immunologic factors that increase the risk of respiratory infections in Down syndrome [15-18]. The increase risk of respiratory infections probably accounts for the magnified poor outcomes in CF patients with Down syndrome.

It is known for mutations on chromosome 21 to be more phenotypically apparent as in the early onset of Alzheimer's disease seen in Down syndrome patients. However, this association has not been studied in other chromosome mutations such as chromosome 7 in CF patients. Genetic studies are underway to understand the genetic basis of the large variation in Down syndrome phenotypes, which is probably caused by allelic heterogeneity on multiple chromosomes [19].

\section{Conclusions}

CF and Down syndrome can occur concomitantly. Our patient had an enhanced response to ivacaftor which may suggest that although patients with concomitant Down syndrome and CF may have worse lung disease, their response to novel therapies may be intensified. Further studies are needed in this subset of patient population to better characterize CF with trisomy and other genetic disorders.

\section{Additional Information \\ Disclosures}

Human subjects: Consent was obtained by all participants in this study. Conflicts of interest: In 
compliance with the ICMJE uniform disclosure form, all authors declare the following: Payment/services info: All authors have declared that no financial support was received from any organization for the submitted work. Financial relationships: All authors have declared that they have no financial relationships at present or within the previous three years with any organizations that might have an interest in the submitted work. Other relationships: All authors have declared that there are no other relationships or activities that could appear to have influenced the submitted work.

\section{References}

1. Farrell PM: The prevalence of cystic fibrosis in the European Union . J Cyst Fibros. 2008;7, 450-453. 10.1016/j.jcf.2008.03.007

2. Rowe SM, Miller S, Sorscher EJ: Cystic fibrosis. N Engl J Med. 2005, 352:1992-2001. 10.1056/NEJMra043184

3. Rowe SM, Heltshe SL, Gonska T, et al.: GOAL Investigators of the Cystic Fibrosis Foundation Therapeutics Development Network. Clinical mechanism of the cystic fibrosis transmembrane conductance regulator potentiator ivacaftor in G551D-mediated cystic fibrosis. Am J Respir Crit Care Med. 2014, 190:175-184. 10.1164/rccm.201404-07030C

4. McDowell KM, Craven DI: Pulmonary complications of Down syndrome during childhood. J Pediatr. 2011;158, 319-325. 10.1016/j.jpeds.2010.07.023

5. Chamseddin BH, Johnson RF, Mitchell RB: Obstructive sleep apnea in children with Down syndrome: demographic, clinical, and polysomnographic features. Otolaryngol Head Neck Surg. 2019, 160:150-157. 10.1177/0194599818797308

6. Guy EL, Peckham DG, Brownlee KG, Conway SP, Lee TWR: Cystic fibrosis co-existing with trisomy 21 . J Cyst Fibros. 2010, 9:330-331. 10.1016/j.jcf.2010.05.003

7. De Boeck K, Munck A, Walker S, et al.: Efficacy and safety of ivacaftor in patients with cystic fibrosis and a non-G551D gating mutation. J Cyst Fibros. 2014, 13:674-680. 10.1016/j.jcf.2014.09.00

8. Ramsey BW, Davies J, McElvaney NG, et al.: A CFTR potentiator in patients with cystic fibrosis and the G551D mutation. N Engl J Med. 2011, 365:1663-1672. 10.1056/NEJMoa1105185

9. Prudon SL: Cystic fibrosis and Down's syndrome. J Cyst Fibros. 2008, 7:S123. 10.1016/S1569-1993(08)604658

10. Kruger C, Barmeier H, Sailer R, Harms D: Cystic fibrosis in Down's syndrome: diagnostic pitfalls and implications for the clinician. Arch Dis Child. 1998, 78:194. 10.1136/adc.78.2.194a

11. Milunsky A: Cystic fibrosis and Down's syndrome. Pediatrics. 1968, 42:501-504.

12. Cruz NV, Mahmoud SA, Chen H, Lowery-Nordberg M, Berlin K, Bahna SL: Follow-up study of immune defects in patients with dysmorphic disorders. Ann Allergy Asthma Immunol. 2009, 102:426-431. 10.1016/S1081-1206(10)60516-9

13. Burgio GR, Ugazio AG, Nespoli L, Marcioni AF, Bottelli AM, Pasquali F: Derangements of immunoglobulin levels, phytohemagglutinin responsiveness and T and B cell markers in Down's syndrome at different ages. Eur J Immunol. 1975, 5:600-603. 10.1002/eji.1830050904

14. Burgio GR, Lanzavecchia A, Maccario R, Vitiello A, Plebani A, Ugazio AG: Immunodeficiency in Down's syndrome: T-lymphocyte subset imbalance in trisomic children. Clin Exp Immunol. 1978, 33:298-301.

15. Bertrand P, Navarro H, Caussade S, Holmgren N, Sánchez I: Airway anomalies in children with Down syndrome: endoscopic findings. Pediatr Pulmonol. 2003, 36:137-141. 10.1002/ppul.10332

16. Jacobs IN, Gray RF, Todd NW: Upper airway obstruction in children with Down syndrome . Arch Otolaryngol Head Neck Surg. 1996, 122:945-950. 10.1001/archotol.1996.01890210025007

17. Frazier JB, Friedman B: Swallow function in children with Down syndrome: a retrospective study . Dev Med Child Neurol. 1996, 38:695-703. 10.1111/j.1469-8749.1996.tb12139.x

18. Shibahara Y, Sando I: Congenital anomalies of the eustachian tube in Down syndrome. Histopathologic case report. Ann Otol Rhinol Laryngol. 1989, 98:543-547. 10.1177/000348948909800709

19. Lana-Elola E, Watson-Scales SD, Fisher EMC, Tybulewicz VLJ: Down syndrome: searching for the genetic culprits. Dis Model Mech. 2011, 4:586-595. 10.1242/dmm.008078 